\title{
Mechanistic Insights into Pathological Changes in the Diabetic Retina
}

\section{Implications for Targeting Diabetic Retinopathy}

\author{
Sayon Roy, ${ }^{* \dagger}$ Timothy S. Kern, ${ }^{\ddagger \S}$ Brian Song, ${ }^{* \dagger}$ and Caren Stuebe ${ }^{* \dagger}$ \\ From the Departments of Medicine* and Ophthalmology, ${ }^{\dagger}$ Boston University School of Medicine, Boston, Massachusetts; and the Departments of \\ Pharmacology ${ }^{\ddagger}$ and Clinical and Molecular Endocrinology, ${ }^{\S}$ Case Western Reserve University School of Medicine, Cleveland, Ohio
}

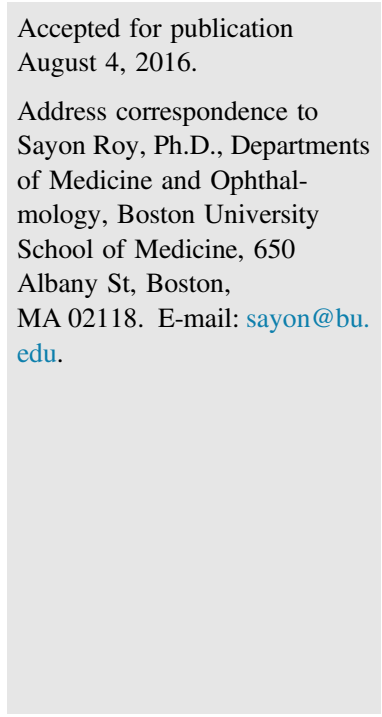

Accepted for publication August 4, 2016.

Address correspondence to Sayon Roy, Ph.D., Departments of Medicine and Ophthalmology, Boston University MA 02118. E-mail: sayon@bu. edu.

Diabetic retinopathy (DR) is a major complication of diabetes and is the leading cause of visual impairment and blindness among working-age adults. ${ }^{1}$ Patients with DR may lose sight as a result of the development of diabetic macular edema (DME) and/or proliferative diabetic retinopathy.

The progression of advanced DR can be inhibited by laser-induced photocoagulation, ${ }^{2}$ but this procedure may destroy parts of the retina. Intravitreal injections of anti-vascular endothelial growth factor therapies ${ }^{3-5}$ or corticosteroids $^{6,7}$ can also appreciably diminish retinal neovascularization and retinal edema, but these injections require frequent visits to a physician and have only transitory beneficial effects in approximately half of treated patients. ${ }^{3}$ Use of corticosteroids may have adverse effects, leading to cataract formation and increased intraocular pressure in a significant number of patients $^{8}$; therefore, its clinical use is limited.

The early stages of DR can be inhibited by improvement of glycemic control using either insulin or oral agents, ${ }^{9,10}$ but this control remains difficult or impossible for many diabetics to achieve and maintain. Thus, there has been considerable effort to identify specific pharmacological targets to inhibit the development of retinopathy. Inhibitors of protein kinase $\mathrm{C}$, aldose reductase (AR), nonenzymatic glycation, and

Supported by the National Eye Institute grants NIH EY018218 and EY025528 (S.R.), the Boston University Undergraduate Research Opportunities Program award (B.S.), and a Merit grant from the Department of Veteran Affairs (T.S.K.).

Disclosures: None declared. 


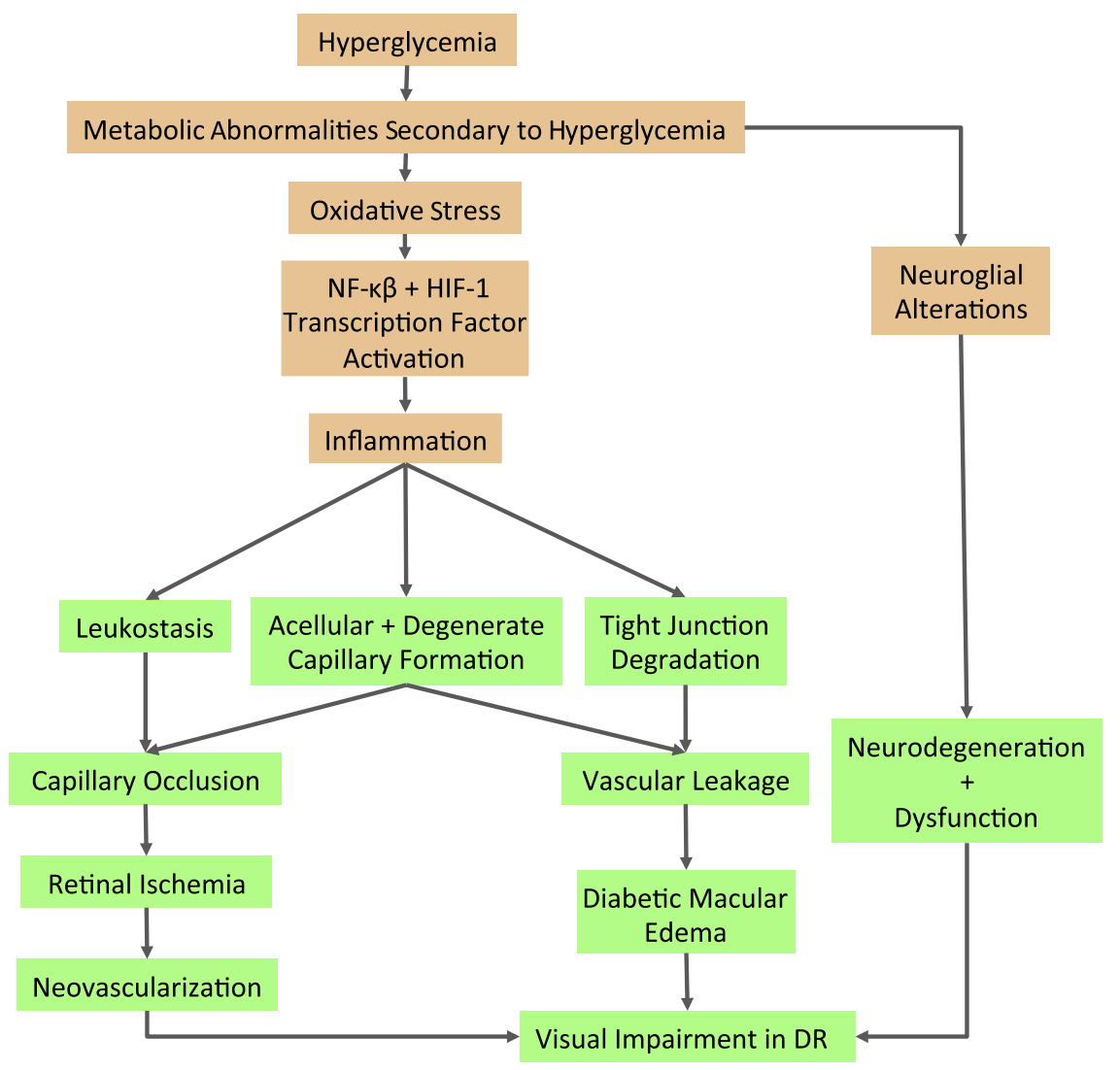

Figure 1 Effects of hyperglycemia (HG) on biochemical pathways and inflammation in diabetic retinopathy (DR) pathogenesis. In the $\mathrm{HG}$ condition, metabolic abnormalities secondary to hyperglycemia contribute to neuroglial alterations that can lead to neurodegeneration and dysfunction. Increased oxidative stress can promote NF- $\kappa B$ and hypoxia-inducible factor (HIF)- 1 activation. In addition, increased activity of proinflammatory cytokine, chemokine, and adhesion molecule can result in tight junction degradation and acellular capillary formation. Leukostasis contributes to capillary occlusion and can lead to retinal ischemia. Diabetes-induced macular edema, and neovascularization, all significant pathological events in DR. The orange boxes represent stages leading to the development of retinal vascular lesions; green boxes, pathological and clinical stages leading to vision loss in DR. vascular endothelial growth factor comprise just a few of the candidates that have been investigated as therapeutic targets against DR, but anti-vascular endothelial growth factor therapy has been unique among pharmacological approaches in showing efficacy in diabetic patients. Therapies developed for conditions other than diabetes or retinopathy, such as blood pressure medications ${ }^{11}$ and fibrates, ${ }^{12}$ also are reported to have beneficial effects on DR, although again only in a subset of diabetic patients. Thus, available therapies for DR are not equally effective in all patients.

\section{Targets of DR Lesions for Which Treatment Is Needed}

Major causes of clinically significant vision loss due to diabetes are generally accepted to be vascular in origin and include retinal edema and preretinal lesions, such as neovascularization, fibrovascular membranes, and hemorrhages. Vascular permeability, local ischemia, and preretinal neovascularization thus have a clear relationship to visual impairment in DR, and are appropriate targets for DR treatment.

Retinal neurons also are adversely affected in diabetes. They become dysfunctional, as evidenced by diabetesinduced changes in electroretinogram, contrast sensitivity, visual acuity, and color sensitivity, and these defects can impair the quality of vision. However, whether the functional defects or the death of retinal neurons contributes to clinically meaningful loss of vision in diabetes is not yet clear. Although many publications attribute the adverse effects of diabetes to neurodegeneration, it is not clear that cell death is the culprit, as opposed to less obvious metabolic or functional defects within remaining neurons. Thus, retinal neurons also might be a therapeutic target to inhibit the retinopathy and accompanying visual impairment or loss. More important, evidence is accumulating that a specialized kind of retinal neuron (photoreceptors) plays an important role in the diabetes-induced degeneration of retinal capillaries, which can subsequently lead to retinal neovascularization. These topics are discussed below.

\section{Mechanisms Implicated in the Pathogenesis of DR}

Although hyperglycemia has been demonstrated to initiate the pathology of DR, appreciable evidence suggests that oxidative stress and inflammatory changes in the retina play critical steps in the pathogenesis of the hyperglycemiainduced retinopathy (Figure 1). Recently, proinflammatory lipids, ${ }^{13}$ epigenetic and epigenomic modifications, ${ }^{14}$ insulin dysregulation, ${ }^{15}$ and $\beta$-cellulin signaling ${ }^{16}$ which initiate and contribute to DR pathogenesis independently from hyperglycemic condition, have been identified. 


\section{Oxidative Stress}

Increased production of reactive oxygen species (ROS) has been frequently identified in diabetic retinas. It appears to be causally involved in the development of the retinopathy as oral administration of antioxidants ${ }^{17}$ or genetic overexpression of superoxide dismutases ${ }^{18}$ has been shown to inhibit the diabetes-induced degeneration of retinal capillaries in animal studies. Moreover, up-regulation of ROS can lead to increased activation of NF- $\kappa \mathrm{B}$, which, in turn, increased the release of proinflammatory cytokines and nitric oxide (NO). Thus, oxidative stress might indirectly contribute to DR secondary to stimulation of inflammation or directly contribute to the retinopathy via oxidative damage to cells. Oxidative stress can be generated in multiple subcellular compartments, and each has been implicated in the pathogenesis of DR.

\section{Mitochondrial Dysfunction}

Hyperglycemia-induced electron transport chain dysfunction, resulting in electron leakage through complex I and complex III, leads to increased superoxide and ROS levels. ${ }^{19}$ In addition, mitochondrial DNA, which codes for 13 essential electron transport chain proteins, is prone to oxidative stress. $^{20}$ Therefore, oxidative stress-induced damage of mitochondrial DNA often leads to impaired transcription of electron transport chain proteins, which compromises electron transport chain function and further escalates ROS production. ${ }^{20,21}$ In addition, the inhibition of superoxides also inhibited glucose-induced release of proapoptotic cytochrome $c$ and Bax in retinal pericytes and endothelial cells, thus further substantiating a causal link between mitochondrial oxidative stress and DR pathogenesis. ${ }^{22}$

\section{Altered Levels of Nox}

NADPH oxidase (Nox) enzymes catalyze the oxidation of NADPH to NADP in the cytosol and the reduction of oxygen across biological membranes to generate superoxide anions. ${ }^{23}$ Nox 2 and Nox 4 isoforms are overexpressed in retinal endothelial cells and vessels under hyperglycemic and hypoxic conditions, leading to elevated ROS production. ${ }^{24}$ Reducing several Nox isoform levels has been shown to alleviate several symptoms of DR, such as retinal neovascularization, blood retinal barrier breakdown, and leukostasis, thus connecting Nox activity to DR pathogenesis. ${ }^{25,26}$

\section{Uncoupled Proteins Influence NO Synthase and ROS Levels}

Uncoupling of NO synthase has been shown to increase superoxide production. ${ }^{27}$ These superoxides can also react with NO to form peroxynitrite, which is a major contributor to cellular injury and oxidative stress. ${ }^{27}$ A polymorphism in the $-3826 A / G$ allele of uncoupling protein (UCP)- 1 has also been reported to diminish $U C P$-1's protective effects against ROS, thus increasing oxidative stress in diabetic patients. ${ }^{28}$ In addition, 866G/A, Ala55Val, and 45-bp insertion/deletion polymorphisms in $U C P-2$ genes have been associated with the promotion of DR by also decreasing $U C P-2$ 's protective effects against ROS. ${ }^{29}$

\section{Inflammation}

Inflammation is a non-specific response by which the innate immune system of a host defends itself after exposure to an antigen or microorganism. Although acute inflammation generally yields beneficial results, such as tissue defense and repair, chronic inflammation often results in more damaging effects, such as cell death in the brain and retina. ${ }^{30}$ Typically, invading pathogens are recognized by pattern recognition receptors, such as Toll-like receptors. Binding of Toll-like receptors to pathogens is mediated by specific protein, carbohydrate, lipid, and nucleic acid sequences on the pathogen, called pathogen-associated molecular patterns. ${ }^{31}$ Activation of the Toll-like receptors facilitates the release of NF- $\kappa \mathrm{B}$, which then translocates into the nucleus to stimulate transcription of proinflammatory chemokines, such as IL-6, tumor necrosis factor- $\alpha$, IL- $1 \beta$, and monocyte chemoattractant protein- $1 .{ }^{31}$ These proinflammatory chemokines play a major role in the recruitment and activation of leukocytes and the subsequent inflammatory responses, as discussed in Diabetes-Mediated Inflammation in Retinal Cell Types and Pathways Involved in Retinal Inflammation and Oxidative Stress in DR.

\section{Inflammation and Diabetic Retinopathy}

Increasing evidence implicates inflammation as a critical contributor to the development of DR. ${ }^{32}$ Many of the inflammatory mediators listed in the previous paragraph are activated in DR, but the signaling involved in initiating this response is less clear. Nevertheless, there is evidence that these inflammatory-like processes contribute to the pathogenesis of DR in both animal and patient studies, in that inhibition of proinflammatory enzymes or deletion of such enzymes inhibits diabetes-induced vascular pathology in animal models of DR. ${ }^{32}$ Studies also have shown that leukocytes play an important role in the structural and functional abnormalities that characterize DR. ${ }^{33,34}$ In patients, the most compelling evidence that inflammatory processes play an important role in DR pathogenesis is the dramatic effect of corticosteroids on DME. ${ }^{7,35}$ Therefore, the specific cell types that mediate these proinflammatory effects are of great interest.

\section{Diabetes-Mediated Inflammation in Retinal Cell Types}

Inflammatory cytokine release and leukocyte adhesion to the retinal vasculature are two hallmarks of early 
inflammation-mediated events in DR. ${ }^{36,37}$ Such events may lead to retinal vascular cells and tight junctions becoming compromised, ${ }^{38,39}$ which can lead to vascular leakage. Inflammatory molecules, such as tumor necrosis factor- $\alpha$, IL-1 $\beta$, IL-6, IL-8, intracellular adhesion molecule-1, vascular cell adhesion molecule 1 , integrin $\beta-2$ (CD-18), and monocyte chemoattractant protein-1, play pivotal roles in the pathogenesis of DR lesions.

High glucose-induced glial cell dysfunction is known to be a facilitator of inflammatory molecule production and release. Müller cells exposed to hyperglycemic conditions produce increased levels of proinflammatory molecules, IL- $8,{ }^{40} \mathrm{NO}$, and cyclooxygenase-2. ${ }^{41}$ Furthermore, one study reported that the density of Müller cells increases significantly under hyperglycemic conditions, ${ }^{42}$ thus potentially leading to escalated production of proinflammatory cytokines. In addition, activated microglia have been observed to up-regulate proinflammatory mediators tumor necrosis factor- $\alpha$, IL- $1 \beta$, IL-6, and macrophage inflammatory protein $-1{ }^{43}$ The resulting glial cell-activated neuroinflammation can thereby contribute to vascular breakdown, while promoting further glial and neuronal cell dysfunction.

\section{Pathways Involved in Retinal Inflammation and Oxidative Stress in DR}

\section{p38 MAPK Pathway}

Studies have shown that the p38 mitogen-activated protein kinase (MAPK) pathway controls other proinflammatory cytokine and chemokine gene expression by regulating NF- $\kappa$ B activity. ${ }^{44,45}$ MAPK plays a significant role in the development of inflammation in the diabetic retina through up-regulation of IL-6. In retinal Müller cells, activation of the p38 MAPK/NF- $\kappa \mathrm{B}$ signaling pathway increases the production of IL-6 via IL-1 $\beta .^{44}$ However, IL-6 possesses proinflammatory, anti-inflammatory, and apoptotic function in the retina. ${ }^{46}$ Pharmacological inhibition of the p38 MAPK pathway significantly inhibited diabetes-induced increases of several lesions characteristic of DR, such as acellular capillaries, pericyte ghosts, and adherent leukocytes in the retinal vasculature. ${ }^{47}$ Inhibition also reduced levels of proinflammatory mediators, such as intracellular adhesion molecule-1, inducible NO synthase, and superoxides. ${ }^{47}$ Therefore, targeting the p38 MAPK pathway may reduce the effects of inflammation in the pathogenesis of DR.

\section{Polyol Pathway}

Under hyperglycemic conditions, AR up-regulates reduction of glucose to sorbital. ${ }^{48}$ Sorbital dehydrogenase oxidizes the excess sorbital to fructose, which concurrently reduces $\mathrm{NAD}^{+}$to NADH. The resultant increase in the intracellular $\mathrm{NADH} / \mathrm{NAD}^{+}$ratio leads to the inhibition of glyceraldehyde-3-phosphate dehydrogenase, which then contributes to increased triose phosphate production. Triose phosphate prompts the activation of advanced glycation end-products and protein kinase $\mathrm{C}$ (PKC) pathways by inducing formation of methylglyoxal, a precursor of diacylglycerol and advanced glycation end-products. ${ }^{49}$ In addition to an increase in sorbital expression, AR up-regulation results in excess oxidation of NADPH to NADP ${ }^{+23}$ The oxidation of NADPH leaves less NADPH available for the production of the intracellular antioxidant, glutathione, thus facilitating the proliferation of ROS.

Although AR inhibitors were not previously considered as treatments for anti-inflammatory effects, studies demonstrated that the inhibitors actually possessed anti-inflammatory effects $^{50,51}$ through potential blocking of glutathione-lipid alcohol species formation. However, a recent clinical trial using AR inhibitor, epalrestat, prevented the progression of diabetic neuropathy, retinopathy, and nephropathy. ${ }^{52}$ A recent study indicated that diabetic mice lacking AR were protected from diabetes-induced reductions in visual function (namely, contrast sensitivity and spatial frequency threshold). ${ }^{53}$

\section{PKC Pathway}

A hyperglycemia-induced increase in ROS and diacylglycerol contributes to the activation of PKC. Up-regulation of PKC results in increased vascular permeability, neovascularization, and capillary apoptosis characteristic of DR. ${ }^{23}$ In addition, PKC increases the activity of Nox, leading to further ROS production, NF- $\kappa \mathrm{B}$ activation, and inflammation, as demonstrated in animal studies. ${ }^{54}$ However, clinical trials failed to validate that inhibition of the PKC pathway adequately inhibited the progression of $\mathrm{DR}^{55}$ but did have effects on visual function. ${ }^{56}$

\section{Novel Therapeutic Approaches and Targets to Inhibit DR}

Recent studies examining the pathogenesis of DR are shedding light into new pharmacological approaches for inhibiting molecular alterations underlying aspects of the disease. ${ }^{57-59}$ Furthermore, studies have also identified new cellular contributors in the retinopathy beyond the common focus solely on the vasculature. ${ }^{58,60,61}$ Several recent lines of evidence have also identified potential new targets for inhibition of DR, and several Food and Drug Administration-approved drugs (against other diseases) have been found to inhibit the diabetes-induced degeneration of retinal capillaries characteristic of DR in diabetic rodents. Some of these repurposed drugs were initially identified as protective against DR in clinical trials, whereas others are being tested now only in animals. Such examples are discussed below.

\section{Anti-Inflammatory Agents}

One anti-inflammatory approach that has been investigated with regard to experimental treatment of experimental DR in 
animal models involves the inhibition of tumor necrosis factor- $\alpha$ with soluble receptor fusion proteins etanercept and pegsunercept. ${ }^{62}$ This treatment has been shown to downregulate intracellular adhesion molecule-1 production, lower intercellular NF- $\mathrm{BB}$ concentrations, and decrease leukostasis and acellular capillary and pericyte ghost formation. ${ }^{62}$

Nonsteroidal anti-inflammatory drugs are a class of drugs that elicit anti-inflammatory effects by inhibiting cyclooxygenase enzyme-mediated prostaglandin formation. ${ }^{63,64}$ At high doses, cyclooxygenase-2 inhibitor meloxicam has been shown to reduce endothelial NO synthase concentrations, ${ }^{62} \mathrm{NF}-\kappa \mathrm{B}$ activation levels, ${ }^{37}$ and leukocyte adhesion ${ }^{62}$ in diabetic retinas. In addition, our study indicates that fenofibrate can reduce high glucose-induced cyclooxygenase-2 up-regulation to exhibit anti-inflammatory effects. ${ }^{65}$ Aspirin has also been shown to significantly reduce the adhesiveness of leukocytes ${ }^{62}$ and, at high doses, to minimize the development of microvascular lesions in patients in non-proliferative DR. ${ }^{64,66,67}$

Leukocytes have been shown to play a major role in the degeneration of retinal capillaries in DR. ${ }^{33,34}$ Leukocyte integrin $\alpha_{\mathrm{m}} \beta_{2}$ (alias CD11b/CD18 or MAC1), a protein mediating adhesion between leukocytes and endothelial cells, has been shown to facilitate such damage to endothelial cells by activating leukocytes. ${ }^{33}$ Diabetes causes a significant increase in leukocyte adhesion to the retinal microvasculature (leukostasis), and selective antagonism of that adhesion by expression of neutrophil inhibitory factor has been shown to inhibit the diabetes-induced degeneration of retinal capillaries. ${ }^{60}$ Leukocytes normally play an important role in immune function, so it is significant that the study also provided evidence that neutrophil inhibitory factor did not inhibit normal immune surveillance. Thus, inhibition of leukocyte adhesion to retinal endothelial cells is a potential therapeutic target to inhibit DR.

\section{Fibrates}

Fenofibrate is known as a cholesterol-lowering agent and lipid-modifying drug that regulates the expression of many different genes, with a range of beneficial effects on inflammation, angiogenesis, extracellular matrix overexpression, and cell apoptosis. Results from several clinical trials have demonstrated unexpected benefits also on DR. The Fenofibrate Intervention and Event Lowering in Diabetes study, conducted in Australia, Finland, and New Zealand, reported a $37 \%$ reduction in the need for laser surgery to prevent vision loss, and a 79\% slowing in a two-step progression on the Early Treatment Diabetic Retinopathy Study score in subjects with existing retinopathy. ${ }^{12}$ The Action to Control Cardiovascular Risk in Diabetes eye trial confirmed the beneficial effects of fenofibrate on DR, ${ }^{68}$ showing a similar $40 \%$ reduction in progression of retinopathy with fenofibrate. Fenofibrate recently has been approved for use in Australia to slow the progression of existing DR in patients with type 2 diabetes. Originally considered a lipid-modifying drug, it now appears that multiple mechanisms may underpin the benefit of fenofibrate on diabetic microvascular end points. ${ }^{69}$

\section{G-Protein-Coupled Receptor Agonists and Antagonists}

Guanine nucleotide triphosphate-binding protein (G protein)coupled receptors form a large diverse superfamily of membrane proteins encoded by $>800$ genes in the human genome. ${ }^{70}$ They respond to a variety of extracellular signals, including photons, ions, small organic molecules, and proteins, that lead to conformational changes and cause activation of cytosolic signaling through activation of one or several $\mathrm{G}$ proteins. Subsequently, these G-protein-coupled receptors regulate effector molecules, such as calcium, potassium channels, adenylate cyclase, phospholipase $\mathrm{C}$, and protein kinases.

Recently, two classes of extracellular G-protein-coupled receptors (adrenergic and serotonergic receptors) have been shown to participate also in the pathogenesis of early stages of $\mathrm{DR}$, including the diabetes-induced increase in retinal oxidative stress and expression of proinflammatory proteins. ${ }^{58}$ Moreover, pharmacological inhibition of either the $\alpha_{1}$-adrenergic receptor or downstream NADPH oxidase (both components of the $\mathrm{G}_{\mathrm{q}}$-regulated signaling pathway) with doxazosin or apocyinin, respectively, lowered the diabetes-induced increase in retinal oxidative stress, expression of proinflammatory proteins by the retina, and the resulting degeneration of retinal capillaries. ${ }^{58}$ The results show that overactive $G_{q}$ signaling plays a causal role in the development of DR.

Likewise, there is also evidence for a role of the $\beta$-adrenergic receptor in DR pathogenesis. $\beta$-Adrenergic receptors signal via the $G_{s}$ pathway, leading to the accumulation of cyclic adenosine monophosphate. Loss of adrenergic input is common in diabetes, and treatment with $\beta$-adrenergic receptor antagonists ${ }^{71}$ or deletion of $\beta_{2}$-adrenergic receptors in mice ${ }^{72}$ replicated features of DR, even in the absence of diabetes. Compound $49 \mathrm{~b}$, a $\beta 1 / \beta 2$-adrenergic receptor agonist, inhibited the diabetesinduced degeneration of retinal capillaries and loss of capillary pericytes and ganglion cells. ${ }^{73}$ In addition, daily administration of the $\beta$-adrenergic receptor agonist, isoproterenol, significantly reduced the diabetes-induced loss of electroretinographic amplitudes, inhibited apoptosis of retinal neural cells, and decreased the numbers of degenerate capillaries. $^{71,74,75}$

\section{Photoreceptors and Modulation of the Visual Cycle}

Photoreceptors and retinal pigment epithelium (RPE) of the outer retina form a functional unit inasmuch as both cells are needed to complete the visual cycle for vision. However, neither of these cells has been commonly regarded as important in the pathogenesis of DR. Nevertheless, 
accumulating evidence raises a possibility that the unique susceptibility of the retina to injury in diabetes may, in fact, be because of the effects of photoreceptors and/or RPE.

$\operatorname{Arden}^{76}$ sent a survey to a group of diabetic patients who also had retinitis pigmentosa, and found that DR seemed less severe in diabetics who also had retinitis pigmentosa (and therefore, photoreceptor degeneration). de Gooyer et $\mathrm{al}^{77}$ subsequently reported that diabetes did not cause the expected decrease in density of the retinal microvasculature in mice lacking most photoreceptors secondary to deficiency of opsin $\left(\mathrm{Rho}^{-1-}\right)$. We recently confirmed this using opsindeficient mice and in mice having a $P 23 H$ mutant opsin knocked in, and extended this observation by showing that the stress in photoreceptors undergoing degeneration greatly exacerbated capillary degeneration, but that this stress is reduced after the photoreceptors have degenerated. Photoreceptors do not characteristically degenerate because of diabetes ${ }^{78}$ so they manifest a continuous stress that includes increased oxidative stress ${ }^{60}$ and affects the vasculature.

Hypotheses that might help explain how photoreceptors influence the development of DR include hypoxia ${ }^{79,80}$ and oxidative stress. ${ }^{60}$ These hypotheses are not mutually exclusive.

\section{RPE Data}

The RPE is a specialized epithelium that affects photoreceptor (and thus, retinal) function and integrity. Main functions of the RPE include transport of nutrients, ions, and water, absorption of light, protection against photooxidation, reisomerization of all-trans-retinal into 11-cisretinal, which is crucial for the visual cycle, phagocytosis of shed photoreceptor membranes, and secretion of essential factors for the structural integrity of the retina. ${ }^{81}$ Diabetes has been found to affect many of these functions, but the contribution of the RPE to the pathogenesis of DR remained largely unknown. Nevertheless, several abnormalities induced in RPE in diabetes (excessive production of vascular endothelial growth factor, subnormal production of pigment epithelium-derived factor, ${ }^{82}$ and increased permeability across the RPE ${ }^{83,84}$ potentially allowing excessive water influx into the retina ${ }^{83}$ ) have a clear relationship with the retinopathy.

The role of RPE in early retinal vascular abnormalities of diabetes was recently tested. ${ }^{59}$ Retinylamine is an analog of vitamin A that is selectively retained by only two tissues in the body, RPE and liver. It is an effective trap for reactive aldehydes, and is known to inhibit the RPE-specific protein $65 \mathrm{kDa},{ }^{85,86}$ an enzyme of the visual cycle that converts alltrans-retinol esters back to 11-cis-retinal. ${ }^{87,88}$ Administration of retinylamine once per week to diabetic mice significantly inhibited the diabetes-induced increase in retinal production of superoxide and expression of proinflammatory proteins. More important, this therapy, which acts in the RPE, also inhibited retinal lesions that are clinically relevant in DR (degeneration of retinal capillaries and increased permeability). ${ }^{59}$ The available data suggest that RPE cells and possibly also the visual cycle contribute to the development of DR. Neither the RPE nor enzymes of the visual cycle have previously been identified as potential contributors to the pathogenesis of DR or as potential targets for therapeutic inhibition of DR.

\section{Photobiomodulation}

Photobiomodulation is the application of low-level light that has a biological effect. Numerous studies have shown that light in the far-red to near-infrared region of the spectrum (630 to $1000 \mathrm{~nm}$ ) can have beneficial effects in vitro and in vivo to heal existing tissue damage and to inhibit the development of tissue pathology. ${ }^{89-92}$ Studies related to the retina likewise have demonstrated that the low-intensity far-red $(670 \mathrm{~nm})$ light treatment mitigates pathology in retinal degeneration models ${ }^{93,94}$ and, recently, also in DR. ${ }^{95,96}$ In both diabetic albino rats $^{96}$ and pigmented mice, ${ }^{97}$ whole-body exposure to far-red light $(670 \mathrm{~nm})$ for only 4 minutes per day from the onset of diabetes or as an intervention mitigated abnormalities that are believed to contribute to DR, including increased generation of superoxide, induction of a local proinflammatory environment, and dysfunction or degeneration of retinal neurons. Consistent with this, daily photobiomodulation administered to a small series of diabetic patients having non-centerinvolved macular edema was associated with the gradual reduction in retinal thickness. ${ }^{95}$

Arden et $\mathrm{al}^{98}$ likewise used light to exert a beneficial effect on DME. In one study, they used trans-eyelid retinal illumination of one eye in patients with DR during sleep throughout a 3-month period, and found a reduction in the number of hemorrhages and microaneurysms compared to the contralateral eyes. ${ }^{98}$ In another study by the same group, diabetic patients with early (non-sight-threatening) DME wore a mask that illuminated one closed eye with 505-nm light over 6 months while they slept. ${ }^{57}$ This treatment likewise showed regression of DME and improved visual function. They postulated that avoiding periods of darkness by providing weak nocturnal illumination reduced metabolic activity of rods, thereby reducing the hypoxia that develops in the retina, especially when the vasculature is compromised (such as in diabetes).

\section{Connexins}

Studies have demonstrated that the gap junction protein, connexin $43(\mathrm{Cx} 43)$, plays a critical role in regulating intracellular communication and vascular homeostasis in the retina. ${ }^{99,100}$ Down-regulation of $\mathrm{Cx} 43$ expression subsequently decreases cell-cell communication to promote vascular cell death and vascular permeability under high glucose conditions. ${ }^{100}$ However, the role of high 
glucose-induced changes in $\mathrm{Cx} 43$ expression in human $\mathrm{DR}$, and the potential application of this knowledge in the treatment of DR, is only beginning to be understood. Our findings demonstrated that high glucose-induced Cx43 up-regulation may have protective effects on retinal Müller cells, ${ }^{99}$ whereas a decreased level of $\mathrm{Cx} 43$ alone is sufficient to induce retinal vascular cell apoptosis. ${ }^{100}$ Likewise, reduced levels of $\mathrm{Cx} 43$ are associated with retinal vascular lesions in human DR. ${ }^{61}$

\section{Neuroprotectants}

Although there is evidence that the death of retinal neurons develops before that of vascular cells in both animal and human models, ${ }^{101}$ suggesting the importance of neurodegeneration in the pathogenesis of DR, it is not yet clear that cell death is the culprit, as opposed to less obvious metabolic or functional defects within remaining neurons. Nonetheless, neuroprotective treatment strategies have been shown to treat retinopathy and accompanying visual impairment or loss. ${ }^{102}$ Pigment epithelium-derived factor injections in diabetic rats have been shown to suppress induction of glial fibrillary acidic protein, reduce oxidative stress-mediated neurodegeneration, and inhibit blood retinal barrier breakdown in diabetes. ${ }^{103}$ In addition, intravitreal injections of pigment epithelium-derived factor in diabetic rats protected retinal neurons from glutamate toxicity, likely by decreasing IL-1 $\beta$ levels. ${ }^{104}$ Intravitreal injections of exogenous erythropoietin inhibit retinal cell death and protect blood retinal barrier structure in diabetic rats ${ }^{105}$ and improve visual acuity in patients with chronic DME. ${ }^{106}$ Administration of a somatostatin analog had a direct antiangiogenic effect in the retina of patients with proliferative diabetic retinopathy. ${ }^{107}$

\section{Are Laboratory Rodent Models of DR Suitable for the Assessment of Potential Therapies?}

Rodent models of diabetes have played a critical role in improving our understanding of the pathogenesis of diabetic retinopathy. These animal models were used for identification of biochemical and structural changes associated with structural or functional defects of the retina in diabetes. ${ }^{24,49,80,108}$ Investigators have made significant progress in identifying changes associated with gene expression in different retinal cell types, and biochemical sequelae triggered by hyperglycemia, which have contributed to improved understanding of the development of molecular and cellular events that occur in DR. ${ }^{100,109-112}$

Despite the enormous popularity of rodent models in DR research, the applicability and suitability of rodent models for the assessment of potential therapies remains an open question. Rodent models have certainly proved useful in providing much of our current understanding regarding the response of the retinal cells to the diabetic milieu, and it is expected that these models would continue to provide insight into the molecular mechanisms contributing to specific abnormalities, including capillary degeneration, vascular permeability, and neovascularization. However, the rodent model has its limitations for the study of DR, because it lacks the macula, the region responsible for vision acuity, which is severely affected in diabetes. This makes it inherently difficult to study mechanisms underlying the development and progression of DME as well as development of new therapies directed for macularelated diseases. It is certain that while rodent models will retain their usefulness and applicability in the area of research, other animal models would offer the ability to study unique areas presently lacking in the rodent models.

\section{Primates}

Primates are evolutionarily closer to humans than rodents and, therefore, knowledge gained from studying primate models of diseases is likely to be more physiologically relevant and applicable toward treatment strategies for humans. Significant impediments in using the primate model for DR research currently are the long durations for retinopathy to develop in primates, and the cost involved in maintaining these primates in institutional animal research facilities over that interval. The common marmoset, a new world primate, has been shown to be an excellent model for studying diseases, including ocular diseases such as exudative age-related macular degeneration with choroidal neovascularization, glaucoma, and myopia. ${ }^{13-116}$

Experimentally galactosemic marmosets recently have been shown to develop lesions that are characteristic of nonproliferative DR in patients (including degenerate capillaries, microaneurysms, and vascular permeability) within 2 years of disease onset. ${ }^{117,118}$ There are two significant additional features of this primate model. The first is that these animals are small, and so are well suited for the space limitations of most research facilities. The second is that, in addition to the lesions of early DR, galactose-fed marmosets develop also DME, which cannot be studied in any rodent models of diabetes (rodents and other laboratory animals lack a macula). Therefore, this model offers a unique platform for studying vascular and macular changes in diabeticlike retinopathy as well as testing novel drugs in an animal model that is a step closer to human DR.

\section{Conclusions}

Ongoing research continues to offer new insights into the pathogenesis of DR. Vascular lesions seem to account for most clinically meaningful vision loss in DR, but accumulating evidence shows that multiple different cell types (from inside and outside the eye) actively contribute to the development of those structural and functional changes that compose the retinopathy. Each of these different cell types and molecular alterations identified offer new potential therapeutic sites at which to inhibit the retinopathy. Studies 
to date have offered statistical insight on the efficacy of a given therapy toward a population of patients or animals, but biomarkers or other ways to predict which patients are most at risk of developing sight-threatening DR, or who will respond to a particular therapy, are needed in the future.

\section{References}

1. Centers for Disease Control and Prevention: National diabetes statistics report: estimates of diabetes and its burden in the United States, 2014. Atlanta, GA, CDC, 2014. Available at https://www.cdc.gov/diabetes/ pubs/statsreport14/national-diabetes-report-web.pdf (accessed January 4, 2016)

2. The Diabetic Retinopathy Study Research Group: Photocoagulation treatment of proliferative diabetic retinopathy: clinical application of Diabetic Retinopathy Study (DRS) findings, DRS report number 8 . Ophthalmology 1981, 88:583-600

3. Elman MJ, Aiello LP, Beck RW, Bressler NM, Bressler SB, Edwards AR, Ferris FL 3rd, Friedman SM, Glassman AR, Miller KM, Scott IU, Stockdale CR, Sun JK; Diabetic Retinopathy Clinical Research Network: Randomized trial evaluating ranibizumab plus prompt or deferred laser or triamcinolone plus prompt laser for diabetic macular edema. Ophthalmology 2010, 117:1064-1077e35

4. Nguyen QD, Brown DM, Marcus DM, Boyer DS, Patel S, Feiner L, Gibson A, Sy J, Rundle AC, Hopkins JJ, Rubio RG, Ehrlich JS; RISE and RIDE Research Group: Ranibizumab for diabetic macular edema: results from 2 phase III randomized trials: RISE and RIDE. Ophthalmology 2012, 119:789-801

5. Jardeleza MS, Miller JW: Review of anti-VEGF therapy in proliferative diabetic retinopathy. Semin Ophthalmol 2009, 24:87-92

6. Grover D, Li TJ, Chong CC: Intravitreal steroids for macular edema in diabetes. Cochrane Database Syst Rev 2008, (1):CD005656

7. Silva PS, Sun JK, Aiello LP: Role of steroids in the management of diabetic macular edema and proliferative diabetic retinopathy. Semin Ophthalmol 2009, 24:93-99

8. Erol N, Topba S: Complications of intravitreal triamcinolone acetonide. Surv Ophthalmol 2009, 54:427; author reply-8

9. The Diabetes Control and Complications Trial Research Group: The effect of intensive treatment of diabetes on the development and progression of long-term complications in insulin-dependent diabetes mellitus. N Engl J Med 1993, 329:977-986

10. UK Prospective Diabetes Study Group: Efficacy of atenolol and captopril in reducing risk of macrovascular and microvascular complications in type 2 diabetes: UKPDS 39. BMJ 1998, 317:713-720

11. UK Prospective Diabetes Study Group: Tight blood pressure control and risk of macrovascular and microvascular complications in type 2 diabetes: UKPDS 38. BMJ 1998, 317:703-713

12. Keech AC, Mitchell P, Summanen PA, O’Day J, Davis TM, Moffitt MS, Taskinen MR, Simes RJ, Tse D, Williamson E, Merrifield A, Laatikainen LT, d'Emden MC, Crimet DC, O'Connell RL, Colman PG: Effect of fenofibrate on the need for laser treatment for diabetic retinopathy (FIELD study): a randomised controlled trial. Lancet 2007, 370:1687-1697

13. Crosby-Nwaobi R, Chatziralli I, Sergentanis T, Dew T, Forbes A, Sivaprasad S: Cross talk between lipid metabolism and inflammatory markers in patients with diabetic retinopathy. J Diabetes Res 2015, 2015:191382

14. Kowluru RA, Mishra M: Contribution of epigenetics in diabetic retinopathy. Sci China Life Sci 2015, 58:556-563

15. Gardner TW, Abcouwer SF, Barber AJ, Jackson GR: An integrated approach to diabetic retinopathy research. Arch Opthalmol 2011, 129: 230-235

16. Anand-Apte B, Ebrahem Q, Cutler A, Farage E, Sugimoto M, Hollyfield J, Folkman J: Betacellulin induces increased retinal vascular permeability in mice. PLoS One 2010, 5:e13444
17. Kowluru RA, Tang J, Kern TS: Abnormalities of retinal metabolism in diabetes and experimental galactosemia, VII: effect of long-term administration of antioxidants on the development of retinopathy. Diabetes 2001, 50:1938-1942

18. Kanwar M, Chan PS, Kern TS, Kowluru RA: Oxidative damage in the retinal mitochondria of diabetic mice: possible protection by superoxide dismutase. Invest Ophthalmol Vis Sci 2007, 48: 3805-3811

19. Murphy MP: How mitochondria produce reactive oxygen species. Biochem J 2009, 417:1-13

20. Scarpulla RC: Nucleus-encoded regulators of mitochondrial function: integration of respiratory chain expression, nutrient sensing and metabolic stress. Biochim Biophys Acta 2012, 1819:1088-1097

21. Madsen-Bouterse SA, Zhong Q, Mohammad G, Ho YS, Kowluru RA: Oxidative damage of mitochondrial DNA in diabetes and its protection by manganese superoxide dismutase. Free Radic Res 2010, 44:313-321

22. Kowluru RA, Abbas SN: Diabetes-induced mitochondrial dysfunction in the retina. Invest Ophthalmol Vis Sci 2003, 44:5327-5334

23. Kowluru RA, Mishra M: Oxidative stress, mitochondrial damage and diabetic retinopathy. Biochim Biophys Acta 2015, 1852: $2474-2483$

24. Coucha M, Elshaer SL, Eldahshan WS, Mysona BA, ElRemessy AB: Molecular mechanisms of diabetic retinopathy: potential therapeutic targets. Middle East Afr J Ophthalmol 2015, 22: 135-144

25. Al-Shabrawey M, Bartoli M, El-Remessy A, Ma G, Matragoon S, Lemtalsi T, Caldwell RW, Caldwell RB: Role of NADPH oxidase and STAT3 in statin-mediated protection against diabetic retinopathy. Invest Ophthalmol Vis Sci 2008, 49:3231-3238

26. Al-Shabrawey M, Bartoli M, El-Remessy AB, Platt DH, Matragoon S, Behzadian MA, Caldwell RW, Caldwell RB: Inhibition of $\mathrm{NAD}(\mathrm{P}) \mathrm{H}$ oxidase activity blocks vascular endothelial growth factor overexpression and neovascularization during ischemic retinopathy. Am J Pathol 2005, 167:599-607

27. Narayanan SP, Rojas M, Suwanpradid J, Toque HA, Caldwell RW, Caldwell RB: Arginase in retinopathy. Prog Retin Eye Res 2013, 36: 260-280

28. Brondani LA, de Souza BM, Duarte GC, Kliemann LM, Esteves JF, Marcon AS, Gross JL, Canani LH, Crispim D: The UCP1 -3826A/G polymorphism is associated with diabetic retinopathy and increased UCP1 and MnSOD2 gene expression in human retina. Invest Ophthalmol Vis Sci 2012, 53:7449-7457

29. Crispim D, Fagundes NJ, dos Santos KG, Rheinheimer J, Boucas AP, de Souza BM, Macedo GS, Leiria LB, Gross JL, Canani LH: Polymorphisms of the UCP2 gene are associated with proliferative diabetic retinopathy in patients with diabetes mellitus. Clin Endocrinol 2010, 72:612-619

30. Hotamisligil GS: Inflammation and metabolic disorders. Nature 2006, 444:860-867

31. Jialal I, Kaur H: The role of Toll-like receptors in diabetes-induced inflammation: implications for vascular complications. Curr Diab Rep 2012, 12:172-179

32. Tang J, Kern TS: Inflammation in diabetic retinopathy. Prog Retin Eye Res 2011, 30:343-358

33. Joussen AM, Murata T, Tsujikawa A, Kirchhof B, Bursell SE, Adamis AP: Leukocyte-mediated endothelial cell injury and death in the diabetic retina. Am J Pathol 2001, 158:147-152

34. Talahalli R, Zarini S, Tang J, Li G, Murphy R, Kern TS, GubitosiKlug RA: Leukocytes regulate retinal capillary degeneration in the diabetic mouse via generation of leukotrienes. J Leukoc Biol 2013, 93:135-143

35. Gomez-Ulla F, Marticorena J, Alfaro DV 3rd, Fernandez M, Mendez ER, Rothen M: Intravitreal triamcinolone for the treatment of diabetic macular edema. Curr Diabetes Rev 2006, 2:99-112

36. Adamiec-Mroczek J, Oficjalska-Mlynczak J, Misiuk-Hojlo M: Roles of endothelin-1 and selected proinflammatory cytokines in the 
pathogenesis of proliferative diabetic retinopathy: analysis of vitreous samples. Cytokine 2010, 49:269-274

37. Kern TS: Contributions of inflammatory processes to the development of the early stages of diabetic retinopathy. Exp Diabetes Res 2007, 2007:95103

38. Behl Y, Krothapalli P, Desta T, DiPiazza A, Roy S, Graves DT: Diabetes-enhanced tumor necrosis factor-alpha production promotes apoptosis and the loss of retinal microvascular cells in type 1 and type 2 models of diabetic retinopathy. Am J Pathol 2008, 172:1411-1418

39. Aveleira CA, Lin CM, Abcouwer SF, Ambrosio AF, Antonetti DA: TNF-alpha signals through PKCzeta/NF-kappaB to alter the tight junction complex and increase retinal endothelial cell permeability. Diabetes 2010, 59:2872-2882

40. Liu X, Ye F, Xiong H, Hu D, Limb GA, Xie T, Peng L, Yang W, Sun Y, Zhou M, Song E, Zhang DY: IL-1beta upregulates IL-8 production in human Muller cells through activation of the p38 MAPK and ERK1/2 signaling pathways. Inflammation 2014, 37: $1486-1495$

41. Du Y, Sarthy VP, Kern TS: Interaction between NO and COX pathways in retinal cells exposed to elevated glucose and retina of diabetic rats. Am J Physiol Regul Integr Comp Physiol 2004, 287: R735-R741

42. Rungger-Brandle E, Dosso AA, Leuenberger PM: Glial reactivity, an early feature of diabetic retinopathy. Invest Ophthalmol Vis Sci 2000, 41:1971-1980

43. Grigsby JG, Cardona SM, Pouw CE, Muniz A, Mendiola AS, Tsin AT, Allen DM, Cardona AE: The role of microglia in diabetic retinopathy. J Ophthalmol 2014, 2014:705783

44. Liu X, Ye F, Xiong H, Hu DN, Limb GA, Xie T, Peng L, Zhang P, Wei Y, Zhang W, Wang J, Wu H, Lee P, Song E, Zhang DY: IL1 beta induces IL-6 production in retinal Muller cells predominantly through the activation of $\mathrm{p} 38 \mathrm{MAPK} / \mathrm{NF}-\mathrm{kappaB}$ signaling pathway. Exp Cell Res 2015, 331:223-231

45. Saccani S, Pantano S, Natoli G: p38-Dependent marking of inflammatory genes for increased NF-kappa B recruitment. Nat Immunol 2002, 3:69-75

46. Scheller J, Chalaris A, Schmidt-Arras D, Rose-John S: The pro- and anti-inflammatory properties of the cytokine interleukin-6. Biochim Biophys Acta 2011, 1813:878-888

47. Du Y, Tang J, Li G, Berti-Mattera L, Lee CA, Bartkowski D, Gale D, Monahan J, Niesman MR, Alton G, Kern TS: Effects of p38 MAPK inhibition on early stages of diabetic retinopathy and sensory nerve function. Invest Ophthalmol Vis Sci 2010, 51:2158-2164

48. Kowluru RA, Chan PS: Oxidative stress and diabetic retinopathy. Exp Diabetes Res 2007, 2007:43603

49. Brownlee M: Biochemistry and molecular cell biology of diabetic complications. Nature 2001, 414:813-820

50. Ramana KV, Srivastava SK: Aldose reductase: a novel therapeutic target for inflammatory pathologies. Int J Biochem Cell Biol 2010, 42:17-20

51. Srivastava SK, Yadav UC, Reddy AB, Saxena A, Tammali R, Shoeb M, Ansari NH, Bhatnagar A, Petrash MJ, Srivastava S, Ramana KV: Aldose reductase inhibition suppresses oxidative stressinduced inflammatory disorders. Chem Biol Interact 2011, 191: $330-338$

52. Hotta N, Kawamori R, Fukuda M, Shigeta Y; Aldose Reductase Inhibitor-Diabetes Complications Trial Study Group: Long-term clinical effects of epalrestat, an aldose reductase inhibitor, on progression of diabetic neuropathy and other microvascular complications: multivariate epidemiological analysis based on patient background factors and severity of diabetic neuropathy. Diabet Med 2012, 29:1529-1533

53. Lee CA, Li G, Patel MD, Petrash JM, Benetz BA, Veenstra A, Amengual J, Von Lintig J, Burant C, Tang J, Kern TS: Diabetesinduced impairment in visual function in mice: contributions of p38 MAPK, RAGE, leukocytes, and aldose reductase. Invest Ophthalmol Vis Sci 2013, 93:135-143
54. Zong H, Ward M, Stitt AW: AGEs, RAGE, and diabetic retinopathy. Curr Diab Rep 2011, 11:244-252

55. PKC-DRS Study Group: The effect of ruboxistaurin on visual loss in patients with moderately severe to very severe nonproliferative diabetic retinopathy: initial results of the Protein Kinase C beta Inhibitor Diabetic Retinopathy Study (PKC-DRS) multicenter randomized clinical trial. Diabetes 2005, 54:2188-2197

56. Aiello LP, Davis MD, Girach A, Kles KA, Milton RC, Sheetz MJ, Vignati L, Zhi XE: Effect of ruboxistaurin on visual loss in patients with diabetic retinopathy. Ophthalmology 2006, 113:2221-2230

57. Arden GB, Jyothi S, Hogg CH, Lee YF, Sivaprasad S: Regression of early diabetic macular oedema is associated with prevention of dark adaptation. Eye (London, England) 2011, 25:1546-1554

58. Du Y, Cramer M, Lee C, Tang J, Muthusamy A, Antonetti D, Jin H, Palczewski K, Kern T: Adrenergic and serotonin receptors affect retinal superoxide generation in diabetic mice: relationship to capillary degeneration and permeability. FASEB J 2015, 29:2194-2204

59. Liu H, Tang J, Du Y, Lee CA, Golczak M, Muthusamy A, Antonetti DA, Veenstra AA, Amengual J, von Lintig J, Palczewski K, Kern TS: Retinylamine benefits early diabetic retinopathy in mice. J Biol Chem 2015, 290:21568-21579

60. Du Y, Veenstra A, Palczewski K, Kern TS: Photoreceptor cells are major contributors to diabetes-induced oxidative stress and local inflammation in the retina. Proc Natl Acad Sci U S A 2013, 110: 16586-16591

61. Tien T, Muto T, Zhang J, Sohn EH, Mullins RF, Roy S: Association of reduced connexin 43 expression with retinal vascular lesions in human diabetic retinopathy. Exp Eye Res 2016, 146:103-106

62. Joussen AM, Poulaki V, Mitsiades N, Kirchhof B, Koizumi K, Dohmen S, Adamis AP: Nonsteroidal anti-inflammatory drugs prevent early diabetic retinopathy via TNF-alpha suppression. FASEB J 2002, 16:438-440

63. Agrawal NK, Kant S: Targeting inflammation in diabetes: newer therapeutic options. World J Diabetes 2014, 5:697-710

64. Kastelan S, Tomic M, Gverovic Antunica A, Salopek Rabatic J, Ljubic S: Inflammation and pharmacological treatment in diabetic retinopathy. Mediators Inflamm 2013, 2013:213130

65. Roy S, Kim D, Hernandez C, Simo R, Roy S: Beneficial effects of fenofibric acid on overexpression of extracellular matrix components, COX-2, and impairment of endothelial permeability associated with diabetic retinopathy. Exp Eye Res 2015, 140:124-129

66. The DAMAD Study Group: Effect of aspirin alone and aspirin plus dipyridamole in early diabetic retinopathy: a multicenter randomized controlled clinical trial. Diabetes 1989, 38:491-498

67. Early Treatment Diabetic Retinopathy Study Research Group: Effects of aspirin treatment on diabetic retinopathy: ETDRS report number 8 . Ophthalmology 1991, 98:757-765

68. Chew EY, Ambrosius WT, Davis MD, Danis RP, Gangaputra S, Greven CM, Hubbard L, Esser BA, Lovato JF, Perdue LH, Goff DC Jr, Cushman WC, Ginsberg HN, Elam MB, Genuth S, Gerstein HC, Schubart U, Fine LJ: Effects of medical therapies on retinopathy progression in type 2 diabetes. N Engl J Med 2010, 363: $233-244$

69. Noonan JE, Jenkins AJ, Ma JX, Keech AC, Wang JJ, Lamoureux EL: An update on the molecular actions of fenofibrate and its clinical effects on diabetic retinopathy and other microvascular end points in patients with diabetes. Diabetes 2013, 62:3968-3975

70. Fredriksson R, Lagerstrom MC, Lundin LG, Schioth HB: The Gprotein-coupled receptors in the human genome form five main families: phylogenetic analysis, paralogon groups, and fingerprints. Mol Pharmacol 2003, 63:1256-1272

71. Jiang Y, Walker RJ, Kern TS, Steinle JJ: Application of isoproterenol inhibits diabetic-like changes in the rat retina. Exp Eye Res 2010, 91: $171-179$

72. Jiang Y, Zhang Q, Liu L, Tang J, Kern TS, Steinle JJ: Beta2adrenergic receptor knockout mice exhibit a diabetic retinopathy phenotype. PLoS One 2013, 8:e70555 
73. Zhang Q, Guy K, Pagadala J, Jiang Y, Walker RJ, Liu L, Soderland C, Kern TS, Ferry R Jr, He H, Yates CR, Miller DD, Steinle JJ: Compound 49b prevents diabetes-induced apoptosis through increased IGFBP-3 levels. Invest Ophthalmol Vis Sci 2012, 53:3004-3013

74. Steinle JJ, Chin VC, Williams KP, Panjala SR: Beta-adrenergic receptor stimulation modulates iNOS protein levels through p38 and ERK1/2 signaling in human retinal endothelial cells. Exp Eye Res 2008, 87:30-34

75. Walker RJ, Steinle JJ: Role of beta-adrenergic receptors in inflammatory marker expression in Muller cells. Invest Ophthalmol Vis Sci 2007, 48:5276-5281

76. Arden GB: The absence of diabetic retinopathy in patients with retinitis pigmentosa: implications for pathophysiology and possible treatment. Br J Ophthalmol 2001, 85:366-370

77. de Gooyer TE, Stevenson KA, Humphries P, Simpson DA, Gardiner TA, Stitt AW: Retinopathy is reduced during experimental diabetes in a mouse model of outer retinal degeneration. Invest Ophthalmol Vis Sci 2006, 47:5561-5568

78. Kern TS, Berkowitz BA: Photoreceptors in diabetic retinopathy. J Diabetes Investig 2015, 6:371-380

79. Arden GB, Sivaprasad S: Hypoxia and oxidative stress in the causation of diabetic retinopathy. Curr Diabetes Rev 2011, 7: 291-304

80. Arden GB, Sivaprasad S: The pathogenesis of early retinal changes of diabetic retinopathy. Doc Ophthalmol 2012, 124:15-26

81. Simo R, Villarroel M, Corraliza L, Hernandez C, Garcia-Ramirez M: The retinal pigment epithelium: something more than a constituent of the blood-retinal barrier-implications for the pathogenesis of diabetic retinopathy. J Biomed Biotechnol 2010, 2010:190724

82. Chmielewska K, Robaszkiewicz J, Kosatka M: Role of the retinal pigment epithelium (RPE) in the pathogenesis and treatment of diabetic macular edema (DME). Klin Oczna 2008, 110:318-320

83. Xu HZ, Song Z, Fu S, Zhu M, Le YZ: RPE barrier breakdown in diabetic retinopathy: seeing is believing. J Ocul Biol Dis Infor 2011, 4:83-92

84. Trudeau K, Roy S, Guo W, Hernandez C, Villarroel M, Simo R, Roy S: Fenofibric acid reduces fibronectin and collagen type IV overexpression in human retinal pigment epithelial cells grown in conditions mimicking the diabetic milieu: functional implications in retinal permeability. Invest Ophthalmol Vis Sci 2011, 52:6348-6354

85. Golczak M, Kuksa V, Maeda T, Moise AR, Palczewski K: Positively charged retinoids are potent and selective inhibitors of the trans-cis isomerization in the retinoid (visual) cycle. Proc Natl Acad Sci U S A 2005, 102:8162-8167

86. Golczak M, Imanishi Y, Kuksa V, Maeda T, Kubota R, Palczewski K: Lecithin:retinol acyltransferase is responsible for amidation of retinylamine, a potent inhibitor of the retinoid cycle. J Biol Chem 2005, 280:42263-42273

87. Redmond TM, Poliakov E, Yu S, Tsai JY, Lu Z, Gentleman S: Mutation of key residues of RPE65 abolishes its enzymatic role as isomerohydrolase in the visual cycle. Proc Natl Acad Sci U S A 2005, 102:13658-13663

88. Jin M, Li S, Moghrabi WN, Sun H, Travis GH: Rpe65 is the retinoid isomerase in bovine retinal pigment epithelium. Cell 2005, 122 449-459

89. Desmet KD, Paz DA, Corry JJ, Eells JT, Wong-Riley MT, Henry MM, Buchmann EV, Connelly MP, Dovi JV, Liang HL, Henshel DS, Yeager RL, Millsap DS, Lim J, Gould LJ, Das R, Jett M, Hodgson BD, Margolis D, Whelan HT: Clinical and experimental applications of NIR-LED photobiomodulation. Photomed Laser Surg 2006, 24:121-128

90. Johnstone DM, el Massri N, Moro C, Spana S, Wang XS, Torres N, Chabrol C, De Jaeger X, Reinhart F, Purushothuman S, Benabid AL, Stone J, Mitrofanis J: Indirect application of near infrared light induces neuroprotection in a mouse model of parkinsonism: an abscopal neuroprotective effect. Neuroscience 2014, 274:93-101
91. Lim J, Sanders RA, Snyder AC, Eells JT, Henshel DS, Watkins JB 3rd: Effects of low-level light therapy on streptozotocininduced diabetic kidney. J Photochem Photobiol B 2010, 99: 105-110

92. Yeager RL, Franzosa JA, Millsap DS, Angell-Yeager JL, Heise SS, Wakhungu P, Lim J, Whelan HT, Eells JT, Henshel DS: Effects of 670-nm phototherapy on development. Photomed Laser Surg 2005, $23: 268-272$

93. Albarracin R, Eells J, Valter K: Photobiomodulation protects the retina from light-induced photoreceptor degeneration. Invest Ophthalmol Vis Sci 2011, 52:3582-3592

94. Liang HL, Whelan HT, Eells JT, Meng H, Buchmann E, LerchGaggl A, Wong-Riley M: Photobiomodulation partially rescues visual cortical neurons from cyanide-induced apoptosis. Neuroscience 2006, 139:639-649

95. Tang J, Herda AA, Kern TS: Photobiomodulation in the treatment of patients with non-center-involving diabetic macular oedema. Br J Ophthalmol 2014, 98:1013-1015

96. Tang J, Du Y, Lee CA, Talahalli R, Eells JT, Kern TS: Low-intensity far-red light inhibits early lesions that contribute to diabetic retinopathy: in vivo and in vitro. Invest Ophthalmol Vis Sci 2013, 54: $3681-3690$

97. Saliba A, Du Y, Liu H, Patel S, Roberts R, Berkowitz BA, Kern TS: Photobiomodulation mitigates diabetes-induced retinopathy by direct and indirect mechanisms: evidence from intervention studies in pigmented mice. PLoS One 2015, 10:e139003

98. Arden GB, Gunduz MK, Kurtenbach A, Volker M, Zrenner E, Gunduz SB, Kamis U, Ozturk BT, Okudan S: A preliminary trial to determine whether prevention of dark adaptation affects the course of early diabetic retinopathy. Eye (London, England) 2010, 24: $1149-1155$

99. Muto T, Tien T, Kim D, Sarthy VP, Roy S: High glucose alters Cx43 expression and gap junction intercellular communication in retinal Muller cells: promotes Muller cell and pericyte apoptosis. Invest Ophthalmol Vis Sci 2014, 55:4327-4337

100. Tien T, Muto T, Barrette K, Challyandra L, Roy S: Downregulation of Connexin 43 promotes vascular cell loss and excess permeability associated with the development of vascular lesions in the diabetic retina. Mol Vis 2014, 20:732-741

101. Barber AJ, Lieth E, Khin SA, Antonetti DA, Buchanan AG, Gardner TW: Neural apoptosis in the retina during experimental and human diabetes: early onset and effect of insulin. J Clin Invest 1998, 102:783-791

102. Hernandez C, Dal Monte M, Simo R, Casini G: Neuroprotection as a therapeutic target for diabetic retinopathy. J Diabetes Res 2016, 2016 : 9508541

103. Yoshida Y, Yamagishi S, Matsui T, Jinnouchi Y, Fukami K, Imaizumi T, Yamakawa R: Protective role of pigment epitheliumderived factor (PEDF) in early phase of experimental diabetic retinopathy. Diabetes Metab Res Rev 2009, 25:678-686

104. Shen X, Xie B, Cheng Y, Jiao Q, Zhong Y: Effect of pigment epithelium derived factor on the expression of glutamine synthetase in early phase of experimental diabetic retinopathy. Ocul Immunol Inflamm 2011, 19:246-254

105. Zhang J, Wu Y, Jin Y, Ji F, Sinclair SH, Luo Y, Xu G, Lu L, Dai W, Yanoff M, Li W, Xu GT: Intravitreal injection of erythropoietin protects both retinal vascular and neuronal cells in early diabetes. Invest Ophthalmol Vis Sci 2008, 49:732-742

106. Li W, Sinclair SH, Xu GT: Effects of intravitreal erythropoietin therapy for patients with chronic and progressive diabetic macular edema. Ophthalmic Surg Lasers Imaging 2010, 41:18-25

107. Hernandez C, Simo R: Strategies for blocking angiogenesis in diabetic retinopathy: from basic science to clinical practice. Expert Opin Investig Drugs 2007, 16:1209-1226

108. Ciulla TA, Amador AG, Zinman B: Diabetic retinopathy and diabetic macular edema: pathophysiology, screening, and novel therapies. Diabetes Care 2003, 26:2653-2664 
109. Beltramo E, Porta M: Pericyte loss in diabetic retinopathy: mechanisms and consequences. Curr Med Chem 2013, 20:3218-3225

110. Chronopoulos A, Trudeau K, Roy S, Huang H, Vinores SA, Roy S: High glucose-induced altered basement membrane composition and structure increases trans-endothelial permeability: implications for diabetic retinopathy. Curr Eye Res 2011, 36:747-753

111. Feit-Leichman RA, Kinouchi R, Takeda M, Fan Z, Mohr S, Kern TS, Chen DF: Vascular damage in a mouse model of diabetic retinopathy: relation to neuronal and glial changes. Invest Ophthalmol Vis Sci 2005, 46:4281-4287

112. Wisniewska-Kruk J, Klaassen I, Vogels IM, Magno AL, Lai CM, Van Noorden CJ, Schlingemann RO, Rakoczy EP: Molecular analysis of blood-retinal barrier loss in the Akimba mouse, a model of advanced diabetic retinopathy. Exp Eye Res 2014, 122:123-131

113. Rada JA, Nickla DL, Troilo D: Decreased proteoglycan synthesis associated with form deprivation myopia in mature primate eyes. Invest Ophthalmol Vis Sci 2000, 41:2050-2058
114. Shimazawa M, Masuda T, Nakamura S, Miwa M, Nakamura K, Hara H: An experimental model for exudative age-related macular degeneration with choroidal neovascularization using the common marmoset. Curr Neovasc Res 2015, 12:128-134

115. Shimazawa M, Nakamura S, Miwa M, Tsuruma K, Aihara M, Nakamura K, Hara H: Establishment of the ocular hypertension model using the common marmoset. Exp Eye Res 2013, 111:1-8

116. Troilo D, Judge SJ: Ocular development and visual deprivation myopia in the common marmoset (Callithrix jacchus). Vision Res 1993, 33:1311-1324

117. Chronopoulos A, Roy S, Beglova E, Mansfield K, Wachtman L, Roy S: Hyperhexosemia-induced retinal vascular pathology in a novel primate model of diabetic retinopathy. Diabetes 2015, 64: 2603-2608

118. Tardif SD, Mansfield KG, Ratnam R, Ross CN, Ziegler TE: The marmoset as a model of aging and age-related diseases. ILAR J 2011, $52: 54-65$ 